\title{
A Proposed Cross-Cultural Examination of Online Advertising Effectiveness in China and the UK
}

\author{
Bei Ju ${ }^{1}$ \\ ${ }^{1}$ International Business Faculty, Beijing Normal University Zhuhai Campus, Zhuhai, P. R China \\ Correspondence: Bei Ju, International Business Faculty, Beijing Normal University Zhuhai Campus, Jingfeng \\ Road 18, Tangjia Bay, Zhuhai 519087, People's Republic of China. Tel: 86-756-612-6600. E-mail: \\ jubei@bnuz.edu.cn
}

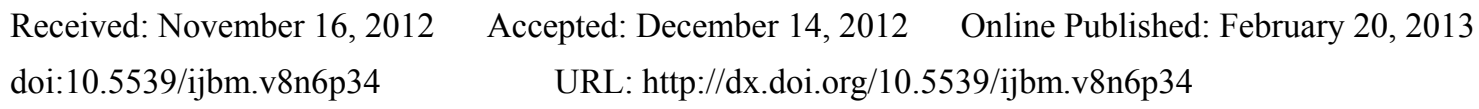

\begin{abstract}
This paper raises a proposed cross-cultural examination of online advertising effectiveness in China and the UK setting against the background of globalization and the widespread usage of online business communication. Different from previous studies, such specific indexes of Hofstede's cultural dimensions as individualism/collectivism, uncertainty avoidance, power distance, masculinity/femininity and long-term orientation which behind the hidden relationships between culture and online advertising effectiveness are suggested to be explored and revealed in the present study based on three measurements including attitudes towards banner ads, ability to recall banner ads and frequency of clicking banner ads. Moreover, the discourse analysis is also advised to be conducted at the same time to evaluate the role of culture in banner advertisement. In this way, the marketers will be enlightened by this study when formulating their online advertising strategies.
\end{abstract}

Keywords: Hofstede's cultural dimensions, online advertising effectiveness, cross-cultural

\section{Introduction}

Along with the emergence of the Internet, the battlefield of marketing is shifting away from conventional media (newspaper, magazine, radio etc.) to online marketing due to its unique characteristics of flexibility, interactivity and low cost. The opportunities consequently have been created for marketers to promote their products and services by means of online advertising. Thus its effectiveness whether online advertising has affected their target consumers is crucial to be measured. Setting against the current trend of globalization, the influence of culture has also drawn the attentions of scholars and researchers when targeting at how to maximize the effectiveness of international advertising (Kyun and Miracle, 2004; Shoop et al., 2008; Terlutter et al., 2010). As a result, these two important factors, namely online advertising and culture should be examined in order to provide more valuable information for international marketers.

\section{Review of Related Literature}

\subsection{The Role of Culture in Online Advertising}

Online advertising has become the important direct marketing channel for the global business. It broadly consists of various commercial content formats delivered by video clip, print and audio (Lim et al. 2011) and includes the means like web sites, pop-ups, banner advertisements, interstitials, interactive games and so on. With the impact of culture recognized on online environments, most studies have examined the relationship of culture and different forms of online advertising. It has been found by Palanisamy (2005) that gender influences the relationships between online consumer characteristics and banner advertisement effectiveness. Baack and Nitish (2007) examine the web sites from 15 countries and conclude that consumers prefer the web sites reflecting their culture. Moreover, Möller and Eisend (2010) introduce and examine a framework to show the influence of national-level cultural variables on banner advertisement effectiveness.

In order to ensure the specific information, the banner advertisement is chosen as online advertising to be examined in the present study based on two main reasons. Firstly, banner advertisement is a standardized type of online advertising which consists of graphic and textual content and contains a link to the advertiser's web site (Manchanda et al. 2006). In comparison with other dynamic forms of online advertising such as video clip and audio, banner advertisement makes it easier for researchers to control and assess its effectiveness. Secondly, it 
accounts for the highest revenues among display-related online advertising according to the statistics of interactive advertising bureau in 2009 and has been used as a major online advertising tool. Its importance has been emphasized by Bhat et al. (2002) that marketers become increasingly concerned about the effectiveness of banner advertisements and most of the online marketing decisions depend on them.

\subsection{Online Advertising Effectiveness and Its Measurement}

Of previous studies concerning about the effectiveness of online advertising, the most common measures include advertisement recall and recognition, clicks-through rate, attitude towards the advertisement, brand awareness (Danaher and Mullarkey, 2003; Dreze and Hussherr, 2003; Gong and Maddox, 2003; Lim et al. 2011). In the specific context of banner advertisement, its effectiveness has been measured through attitude formation, familiarity, recall and recognition in the study of Palanisamy (2005). In the present study, three measures including attitude towards banner ads, ability to recall banner ads and frequency of clicking banner ads will be used to evaluate the effectiveness of online advertising on account of their impact on consumers' online purchase decision and behavior.

Newman et al. (2004) find that attitude towards the web site will be enhanced when there is a congruency between the banner and the web site. Moreover, the study of Palanisamy (2005) indicates that the gender influences consumers' attitude towards banner advertisements. From the perspective of ability to recall banner advertisements, Dreze and Hussherr (2003) report that the advertising recall is influenced by a banner's message. Furthermore, it is found by Yoon (2003) that banner image is more significantly effective than text when assessing consumers' preferences towards online advertisements. In terms of click-through rate which is the average number of times a viewer clicks on the ads and then is exposed to the target web site, it is widely adopted as measure to assess the effectiveness of banner advertisements. The study of Cho (2003) shows that people are more likely to click on banner ads if they are highly involved with the products. Other factors including banner size, animation, message length and banner ad content in the direct responses of viewers are also analyzed in the previous studies (Baltas, 2003; Yoon, 2003).

Upon previous studies, the little empirical evidence exists to indicate how the cultural differences affect the effectiveness of online advertising, especially in different countries. Although some researchers have noticed their relationship, the specific measures of online advertising are rarely combined with the cultural factors. Enlightened by the global investigation of Möller and Eisend (2010) into the cultural antecedents of banner advertising effectiveness, China and the UK, these two countries are to be investigated in this study when exploring the influence of culture.

\section{Motivation and Objectives}

Understanding cultural differences is considered to be a precondition for successful international advertising. Currently, the new communications tool, online advertising, has emerged and widely used by marketers under the circumstances of Information Age. Therefore, how the impact of cultural differences on consumer response to online advertising is of great importance and will affect the marketers' strategy and then their success in advertising campaigns. In order to provide them with more valuable and credible information required in their promotional schemes and decisions, this question will be answered not in general way, but through specific indexes behind which the hidden relationships between culture and online advertising effectiveness will be explored and revealed in the present study.

\section{Theoretical Framework}

\section{Hofstede's cultural dimensions}

Explained by Hofstede (2001), culture is a complex construct that describes the common values and attitudes of a group of human beings and provides a mental software. This dimensional framework of culture is widely accepted in international business and has been supported by researches conducted in dimensions including cross-cultural differences in people's values, beliefs and behavior patterns (Sondergarrd, 1994; Nakata and Sivakumar, 2001; Hofstede 2001). Thus, the five cultural dimensions will be examined in the present study: individualism/collectivism, uncertainty avoidance, power distance, masculinity/femininity and long-term orientation.

Individualism-collectivism is concerned about the relationship between an individual and the collectivity that prevails in a society. According to Hofstede (2001), these two extremes can be contrasted as the "we" society versus the "me" society. China is considered to be a country with a collectivistic culture, which has emphasized social interests and collective actions but deemphasized personal achievements. By contrast, individual success and material prosperity are considered central in the UK. It has been shown by Lee and Tamborini (2005) that 
members in individualist cultures perceive a greater influence of Internet messages on others than people in collectivist.

Uncertainty avoidance is defined by Hofstede (2001, p. 161) as the extent to which the members of a culture feel threatened by uncertain or unknown situations. Cultures that are high in uncertainty avoidance are characterized as intolerance and anxiety in uncertain situations; while cultures that are low in uncertainty avoidance can accept uncertainty and are more prepared to give the benefit of the doubt to the unknown situations (Hofstede, 1991). In other words, people in countries with highness on uncertainty avoidance will stress the strong need for principles, formality and expert advice. Therefore, the influence of this cultural dimension will be further assessed to reveal whether difference of online advertising effectiveness exists in China and the UK due to the lack of sharp contrast in this cultural dimension.

Hofstede (1991, p. 28) explains power distance as the extent to which the less powerful members of institutions and organizations within a country expect and accept that power is distributed unequally. People in countries of high power distance emphasize social hierarchy, authority and paternalism, which are typical characteristics of Chinese. Whereas people in the UK attempt to minimize social inequality but highlight freedom and fairness.

Hofstede (2001) points out that, in general, people in a masculine society believe that a person "lives to work", whereas people in a feminine society are inclined to adopt a "work-to-live" philosophy. Specifically, Steenkamp et al. (1999) show that masculine cultures value ego enhancement, achievement and material things that demonstrate performance and wealth. In contrast, feminine cultures value modesty and avoid showing off, vividly reflected in China.

Long-term orientation refers to a culture's orientation to the future. Cultures with long-term orientations prefer a steady progression toward long-term goals whereas cultures with short-term orientations expect outcomes as soon as possible. As Hofstede notes in 1991 (p. 169) that cultures of short-term orientation show a sensitivity to social trends in consumption, while long-term oriented cultures put emphasis on savings. Based on the explanation mentioned above, Chinese are more apt to the culture of long-term orientation with persistence and thrift while people in the UK reasonably prefer a short-term orientation focusing on personal stability.

The existence of cultural differences in China and the UK should not be denied though the degree of their differences reflected by Hofstede's cultural dimensions varies.

The influence of cultural variables on the online advertising effectiveness in China and the UK

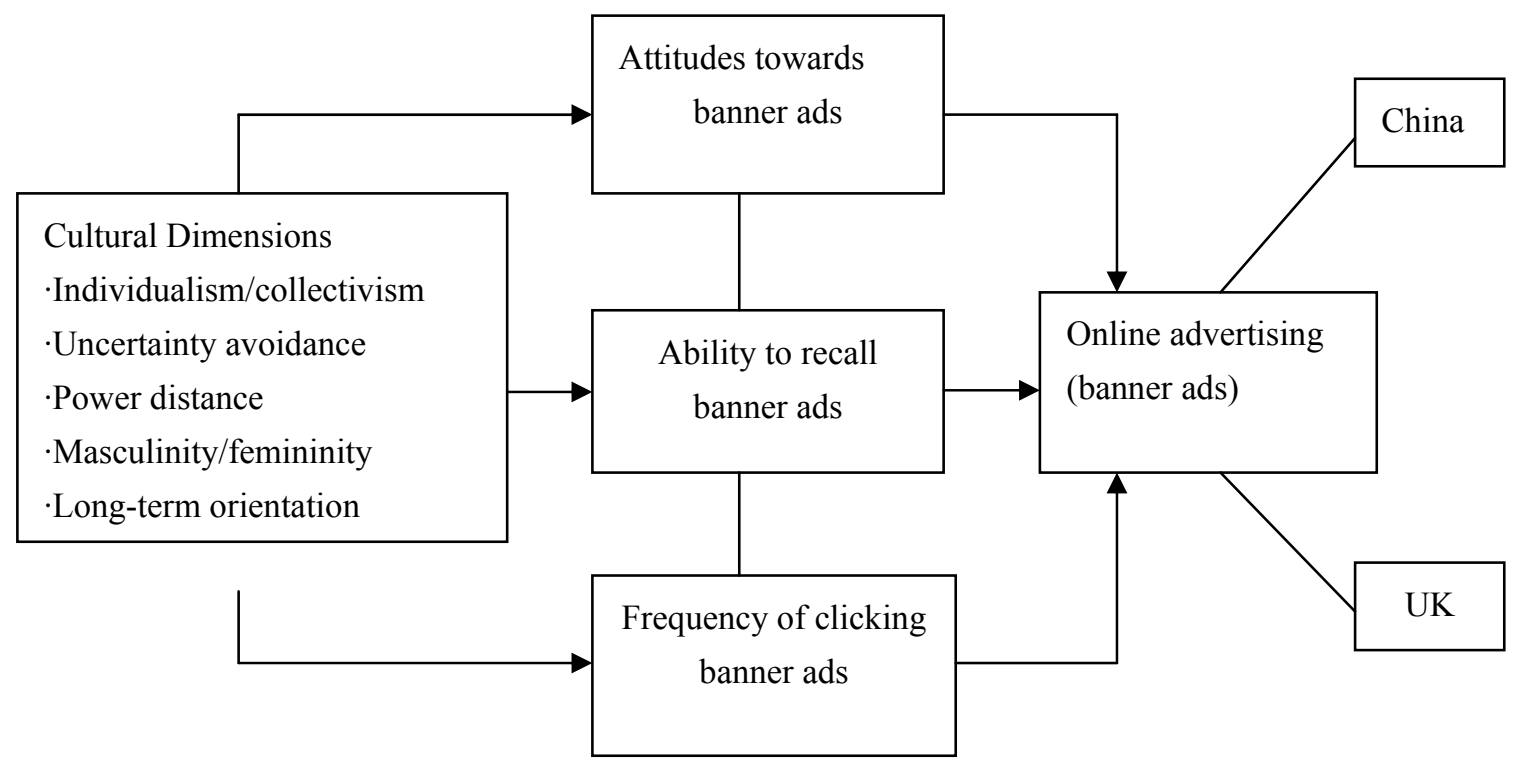

Figure 1. Conceptual framework

In the present study, the effectiveness of online advertising, more specifically, banner advertisements will be measured by three indexes such as attitudes towards banner ads, ability to recall and the click-through rate. The attitudes can be favorable or unfavorable when dealing with the consumers' response to the products. If the attitudes towards the banner advertisement are positive, then its effectiveness is considered to be high and will guide behavior of consumers. The ability to recall means the consumers' competence to recollect or retrieve the 
advertisement from their memory without the stimulation. This measure is comparatively objective. The frequency of clicking is the average number of times a viewer clicks on the ads, which is the main consequence of attitudes towards the advertisement and its recollection.

Meanwhile, the on-line banner advertisement itself from China and the UK on the same products will be conducted by means of discourse analysis to reveal whether there are certain discourse features existing due to geographical and cultural differences.

\section{Research Questions}

In terms of three measures including attitudes, ability to recall and click-through rates,

Question 1: Is the cultural dimension of individualism/collectivism positively associated with the effectiveness of banner advertisements?

H1) a1. Banner advertisements that emphasize individualistic values are more effective in the UK than in China.

H1) a2. Banner advertisements that emphasize collectivistic values are more effective in China than in the UK.

Question 2: Is the cultural dimension of uncertainty avoidance positively associated with the effectiveness of banner advertisements?

H2: Banner advertisements of high uncertainty avoidance do not differ in China and the UK.

Question 3: Is the cultural dimension of power distance positively associated with the effectiveness of banner advertisements?

H3: Banner advertisements of high power distance are more effective in China than in the UK.

Question 4: Is the cultural dimension of masculinity/femininity positively associated with the effectiveness of banner advertisements?

H4) a1. Banner advertisements of masculine values are more effective in the UK than in China.

H4) a2. Banner advertisements of feminine values are more effective in China than in the UK.

Question 5: Is the cultural dimension of long-term orientation positively associated with the effectiveness of banner advertisements?

H5: Banner advertisements that emphasize long-term orientation are more effective in China than in the UK.

H6: There are certain discourse features existing in on-line advertisements due to geographical and cultural differences of China and the UK.

\section{Methodology}

In order to answer the above questions and test the hypotheses, a questionnaire survey will be carried out to collect empirical data. The subjects aged from 18-23 years old will be chosen from large universities located in major metropolitan areas in China and the UK. Subjects will be randomly assigned to each experimental condition. There are three variables in the experiment:

Cultural dimensions - individualism/collectivism, uncertainty avoidance, power distance, masculinity/femininity and long-term orientation;

Measures - attitudes, ability to recall and click-through rates and Country - China and the UK.

These three factors will be complied into a single survey instrument. To ensure the subjects have the same type of banner advertisements in their mind when answering the questions, a sample banner advertisement will be given at the top of the questionnaire. Additionally, the banner advertisements reflecting each of five cultural dimensions will be mainly selected according to the banner text. For example, the banner ad of individualistic values will be read as "Indulge in the joy of self-expression" whereas the collectivistic copy will be "Share the moment of happiness with your friends and family". After viewing the banner advertisements, subjects from China and the UK will complete a questionnaire containing several scales to indicate their responses. For instance, the attitudes towards the banner advertisements will be measured by scales like bad/good, unpleasant/pleasant, unfavorable/favorable. Since the objective of this study is to explore the role of cultural differences in effectiveness of banner advertisements, ANOVA and regression will be employed in testing the proposed questions and hypotheses.

With regards to the examination of the discourse analysis of on-line advertisements, the ideal banner advertisements will be identified to meet the requirements as followings: 1 . The banner advertisements should be adopted to advertise the same brand product both in China and the UK on the company's official website. 2 . The 
products advertised are suggested to be closely related to people's life such as food, clothes, cosmetics, cars, etc. In this way, the differences will be vivid and specific thus its importance will be increasingly widespread and practical.

\section{Outcomes and Value}

Firstly, the influence of culture on online advertising effectiveness will be evident from the result of the present study. Secondly, it is expected that the impact of each cultural dimension will vary when targeting people in China and the UK. According to this result, the marketers are capable of adopting the most effective way to target their consumers by online advertising. Thirdly, the relationships between the culture and three measures of online advertising effectiveness will be of difference. Fourthly, the discourse features of on-line advertising will be exposed to highlight the crucial role of culture in communication. Overall, the findings of this study will not only be limited to give answers to how the cultural factors affect online purchasing decision and behavior but also will provide marketers with implications and confidence in launching their products across the specific country when formulating their online advertising strategies.

\section{References}

Baack, D. W., \& Nitish, S. (2007). Cultural and web communication. Journal of Business Research, 60(3), 181-188. http://dx.doi.org/10.1016/j.jbusres.2006.11.002

Baltas, G. (2003). Determinants of Internet advertising effectiveness: An empirical study. International Journal of Market Research, 45(4), 505-513.

Bhat, S., Bevans, M., \& Sengupta, S. (2002). Measuring users' web activity to evaluate and enhance advertising effectiveness. Journal of Advertising, 31(3), 97-106.

Cho, C. H. (2003). Factors influencing clicking of banner ads on the www. Cyber Psychology and Behavior, 6(2), 201-215. http://dx.doi.org/10.1089/109493103321640400

Danaher, P. J., \& Mullarkey, G. W. (2003). Factors affecting online advertising recall: A study of students. Journal of Advertising Research, 43(3), 252-267. http://dx.doi.org/10.1017/S0021849903030319

Dreze, X. A., \& Hussherr, F. X. (2003). Internet advertising: Is anybody watching? Journal of Interactive Marketing, 17(4), 8-23. http://dx.doi.org/10.1002/dir.10063

Gong, W., \& Maddox, L. M. (2003). Measuring web advertising effectiveness in China. Journal of Advertising Research, 43(1), 34-49.

Hofstede, G. H. (1991). Cultures and Organizations: Software of the Mind. New York: McGraw-Hill.

Hofstede, G. H. (2001). Culture's Consequences: Comparing Values, Behaviors, Institutions and Organizations Across Nations (2nd ed.). Thousand Oaks, CA: Sage Publications.

Hynes, G. E., \& Janson, M. (2007). Global imagery in online advertisement. Business Communication Quarterly, 70(4), 487-492. http://dx.doi.org/10.1177/10805699070700040204

Kyun, C. Y., \& Miracle, E. G. (2004). The effectiveness of comparative advertising in Korea and the United States: A Cross-Cultural and Individual-Level Analysis. Journal of Advertising, 33(4), 75-87.

Lee, B., \& Tamborini, R. (2005). Third-person effect and internet pornography: The influence of collectivism

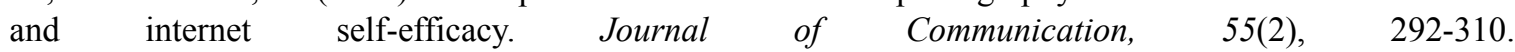
http://dx.doi.org/10.1111/j.1460-2466.2005.tb02673.x

Manchanda, P., Jean-Pieere, D., Khim Yong, G., \& Pradeep, K. C. (2006). The effect of banner advertising on Internet Purchasing. Journal of Marketing Research, 43(1), 98-108. http://dx.doi.org/10.1509/jmkr.43.1.98

Möller, J., \& Eisend, M. (2010). A global investigation into the cultural and individual antecedents of banner advertising effectiveness. Journal of International Marketing, 18(2), 80-89. http://dx.doi.org/10.1509/jimk.18.2.80

Nakata, C., \& Sivakumar, K. (2001). Instituting the marketing concept in a multinational setting: The role of national culture. Journal of the Academy of Marketing Science, 29(3), 255-275. http://dx.doi.org/10.1177/03079459994623

Newman, E. J., Stem, D. E., \& Sprott, D. E. (2004). Banner advertisement and web site congruity effects on consumer web site perceptions. Industrial Management and Data Systems, 104(3), 273-281. http://dx.doi.org/10.1108/02635570410525816

Palanisamy, R. (2005). Impact of gender differences on online consumer characteristics on web-based banner 
advertising effectiveness. Journal of Services Research, 4(2), 45-73.

Shoop, J. T., Luther, A. C., \& McMahan, C. (2008). Advertisement images of men and women in culturally diverging societies: An examination of images in U.S. and Japanese fashion magazines. Journal of International Business and Economics, 8(3), 188-199.

Sondergarrd, M. (1994). Hofstede's consequences: A study of reviews, citations and replications. Organizational Studies, 15(3), 447-456. http://dx.doi.org/10.1177/017084069401500307

Steenkamp, Jan-Benedict, E. M., Hofstede, F., \& Wedel, M. (1999). A cross-national investigation into the individual and national cultural antecedents of consumer innovations. Journal of Marketing, 63(2), 55-69. http://dx.doi.org/10.2307/1251945

Terlutter, R., Diehl, S., \& Mueller, B. (2010). The cultural dimension of assertiveness in cross-cultural advertising: The perception and evaluation of assertive advertising appeals. International Journal of Advertising, 29(3), 369-399. http://dx.doi.org/10.2501/S0265048710201233

Yet-Mee, L., Ching-Seng, Y., \& Tech-Chai, L. (2011). The effectiveness of online advertising in purchase decision: Liking, recall and click. Australian Journal of Basic and Applied Sciences, 5(9), 1517-1524.

Yong, Z., \& Neelankavil, J. P. (1997). The influence of culture on advertising effectiveness in China and the USA: A cross-cultural study. European Journal of Marketing, 31(2), 134-149. http://dx.doi.org/10.1108/03090569710157106

Yoon, S. J. (2003). An experimental approach to understanding banner adverts' effectiveness. Journal of Targeting, Measurement and Analysis for Marketing, 11(3), 255-272. http://dx.doi.org/10.1057/palgrave.jt.5740082 